\title{
Manejo da podridão de melão pelo controle do amadurecimento através do 1-mcp, sob duas condições de armazenamento.
}

\author{
Daniel Terao ${ }^{1}$, Sônia Maria Alves de Oliveira², Francisco Marto Pinto Viana ${ }^{3}$, Cynthia Renata Lima Sá4, Renata \\ Damasceno Moura ${ }^{4}$, Darcy M.F. Gondim ${ }^{5}$.
}

\begin{abstract}
${ }^{1}$ Embrapa Semi-Árido, BR 428, Km 152, CEP 56.300-970, Petrolina, PE, E.mail: daniel.terao@cpatsa.embrapa.br; ${ }^{2}$ UFRPE/DEPA/Fitossanidade, CEP 52171-900, Recife-PE, E.mail: smao@bol.com.br; ${ }^{3}$ Embrapa Agroindústria Tropical, Rua Dr ${ }^{\mathrm{a}}$ Sara Mesquita, 2270, Pici, CEP 60511-110, E.mail: vianafmp@cnpat.embrapa.br; ${ }^{4}$ Mestrandas em Fitotécnia da Universidade Federal Rural do Semi-árido, Mossoró - RN, E.mail: cynthiarenatals@yahoo.com.br; renata_raissa@yahoo.com.br; ${ }^{5}$ Doutoranda em Bioquímica da Universidade Federal do Ceará, E.mail: darcy_mayra@yahoo.com.br
\end{abstract}

Autor para correspondência: Daniel Terao daniel. e-mailterao@cpatsa.embrapa.br

Data de chegada: 06/07/2006. Aceito para publicação em: 29/09/2008

\section{RESUMO}

Terao, D.; Oliveira, S.M.A.; Viana, F.M.P.; Sá, C.R.L.; Moura, R.D.; Gondim, D.M.F. Manejo da podridão de melão pelo controle do amadurecimento através do 1-mcp, sob duas condições de armazenamento. Summa Phytopathologica, v.35, n.2, p.110-115, 2009

Objetivou-se neste trabalho avaliar o efeito de 1-MCP (300 nL.L$\left.{ }^{1}\right)$ nas alterações fisiológicas que ocorrem durante o amadurecimento do melão, tipo Orange cv. Orange Flesh e sua influência no controle da podridão causada por Fusarium pallidoroseum, em dois ambientes de armazenamento, sem refrigeração $\left(29 \pm 1{ }^{\circ} \mathrm{C}\right.$ e umidade relativa de $65 \pm 2 \%)$ e refrigerado $\left(10 \pm 2{ }^{\circ} \mathrm{C}\right.$ e umidade relativa $\left.90 \pm 3 \%\right)$ durante 15 dias e nove dias adicionais em condição ambiente. Avaliouse a atividade respiratória, produção de etileno, perda de matéria fresca, cor da casca e da polpa, firmeza da polpa, $\mathrm{pH}$, acidez total titulável, sólidos solúveis totais, açúcares solúveis totais e severidade da doença. O delineamento foi inteiramente casualizado em arranjo fatorial com quatro repetições/tratamento. Frutos tratados com 1-MCP, armazenados em ambiente sem refrigeração, mantiveram firmeza da polpa praticamente inalterada até o $15^{\circ}$ dia e quando em refrigeração mantiveram-se inalterados até o final da avaliação aos 24 dias após a colheita, retardando também a abscisão do pedúnculo, uma variável indicativa de maturação. $O$ tratamento com 1-MCP retardou o amadurecimento de frutos controlando a podridão de $F$. pallidoroseum. Este tratamento também reduziu a respiração, produção, etileno, perda de peso, não influenciando significativamente as variáveis de qualidade do fruto: coloração da casca e polpa dos frutos, teor de sólidos solúveis totais e açúcares solúveis totais durante o período de armazenamento, bem como $\mathrm{pH}$ e acidez total titulável nas diferentes condições de armazenamento estudadas. A refrigeração interagiu positivamente com o 1-MCP, aumentando o tempo de conservação e sanidade do melão.

Palavras-chave adicionais: Cucumis melo, Fusarium pallidoroseum, 1-metilciclopropeno, pós-colheita.

\section{ABSTRACT}

Terao, D.; Oliveira, S.M.A.; Viana, F.M.P.; Sá, C.R.L.; Moura, R.D.; Gondim, D.M.F. Melon rot management by ripening control whith 1MCP treatment under two storage conditions. Summa Phytopathologica, v.35, n.2, p.110-115, 2009

The objective of this experiment was to evaluate the effect of 1MCP (at $300 \mathrm{~nL} . \mathrm{L}^{-1}$ )on de physiological changes occurring during ripening of Orange type melon fruits cv. Orange flesh and on the control of Fusarium pallidoroseum, causal agent of rot in melon fruit, under two environment conditions at room temperature $(29 \pm$ $\left.1{ }^{\circ} \mathrm{C}\right)$ and $65 \pm 2 \%$ R. H. and at refrigeration temperature $\left(10 \pm 2{ }^{\circ} \mathrm{C}\right.$ and $90 \pm 3 \% \mathrm{RH})$ during 15 days and additional 9 days at room temperature. Respiratory rate, ethylene production, weight loss, skin and pulp color pulp firmness, $\mathrm{pH}$, total soluble sugars, total titrable acidity, total soluble solids, and disease severity were evaluated. The experimental design was completely randomized, factorial with four replicates. Fruit treated with $1-\mathrm{MCP}$ stored at room temperature kept the pulp firmness until $15^{\text {th }}$ day and when combined with refrigeration firmness was kept until the end of evaluation on $24^{\text {th }}$ day after harvest delaying the peduncle abscission. The treatment with 1-MCP delayed fruit ripening by controlling the rot caused by $F$. pallidoroseum. The use of $1-\mathrm{MCP}$ contributed to reduce the respiration, etilene production, weight loss. Non significant changes on skin and pulp color, soluble solids and total soluble sugar was observed during the storage period. For $\mathrm{pH}$ and total titratable acidity the treatment with 1-MCP had no significant effect at both storage conditions.

Keywords: Cucumis melo, Fusarium pallidoroseum, 1-metylcyclopropene, postharvest.

As exportações brasileiras estão sujeitas a vários tipos de barreiras tarifárias e não tarifárias, tais como restrições de caráter sanitário e fitossanitário (2).

Com o objetivo de elevar os padrões de qualidade e competitividade da fruticultura brasileira ao patamar de excelência requerido pelo exigente mercado internacional, o Ministério de Agricultura, Pecuária e Abastecimento (MAPA) implementou o Programa de Produção Integrada de Frutas (PIF), que recomenda no controle de doenças, a 
aplicação do maior número de táticas, visando o controle integrado, priorizando os métodos naturais, biológicos e biotecnológicos, buscando minimizar o nível de resíduos químicos (28).

Uma das estratégias que poderia ser integrada ao controle de podridões é a utilização de técnicas que promovam o prolongamento da vida de prateleira das frutas.

Os frutos são produtos perecíveis, com vida pós-colheita relativamente curta, constitui-se em sistemas biológicos vivos, mesmo depois de destacados da planta mãe, assumindo metabolismo ativo, que caso não seja controlado, compromete a qualidade do produto, diminuindo a sua vida útil. Portanto, é importante conhecer os processos metabólicos no ciclo vital dos frutos, dentre eles a produção de dióxido de carbono $\left(\mathrm{CO}_{2}\right)$ e etileno $\left(\mathrm{C}_{2} \mathrm{H}_{4}\right)$. A presença do etileno em ambientes de armazenamento compromete a qualidade de frutos climatéricos $\mathrm{e}$ não climatéricos por conduzi-los à senescência, sendo indesejável durante o transporte e armazenamento de frutos, considerado um dos grandes vilões da pós-colheita (28).

$\mathrm{O}$ amadurecimento pode ser retardado por meio do uso de inibidores da produção e da ação de etileno $(15,1)$. Entre os inibidores da ação do etileno o 1-metilciclopropeno (1-MCP) tem tido sua eficiência demonstrada em alguns casos, como banana e maçã $(7,9,13,14,18)$. O 1-MCP é um gás que compete com o etileno pelos sítios de ligação nos receptores das membranas (22, 29), podendo retardar ou inibir eventos do amadurecimento dependentes desse fitorregulador (14).

Uma vez que retarda o amadurecimento, o 1-MCP tem sido usado para o controle de inúmeros patógenos em pós-colheita na hipótese de que frutos com amadurecimento mais lento, seriam mais resistentes a podridões (19), como por exemplo, a utilização em maçãs e melão.

A resistência de frutos imaturos à colonização por patógenos pode estar baseada em alguns dos seguintes mecanismos: compostos tóxicos presentes em frutas imaturas como fenóis e taninos, constituindo-se de substâncias complexas inadequadas à nutrição dos patógenos, uma vez que as enzimas produzidas pelo fungo para degradar as substâncias pécticas da parede celular das frutas imaturas são inadequadas ou insuficientes para degradá-los, além da produção de fitoalexinas por frutas imaturas pós-infecção (12).

Outro elemento importante no controle de doenças é o monitoramento da temperatura ambiente. A refrigeração é o processo mais indicado para prolongar a vida pós-colheita das frutas, bem como, para suprimir o desenvolvimento de podridões (4).

Uma das principais podridões que ocorrem em melão é causada por Fusarium pallidoroseum, que sobrevive no solo e em restos de cultura e penetra no fruto pelo pedúnculo durante a colheita $\mathrm{e}$ pelas rachaduras naturais que ocorrem na zona de abscisão peduncular, ou no desenvolvimento das redes em melões do tipo Cantaloupe. Os sintomas aparecem em qualquer parte da fruta, iniciando-se por uma pequena lesão encharcada, acompanhado por um intenso crescimento cotonoso branco. Havendo condições de armazenamento desfavoráveis, com elevada umidade relativa do ar, associada a temperaturas ao redor de $30^{\circ} \mathrm{C}$, ocorre rápida evolução no tamanho da lesão, com aparecimento de fissuras, constituindo-se como porta de entrada para saprófitas oportunistas, que colonizam rapidamente, destruindo completamente os frutos, resultando em sérios prejuízos (6)

Diante do exposto, objetivou-se neste trabalho avaliar a influência do tratamento com 1-MCP no controle de Fusarium pallidoroseum, causador de podridão do fruto e nas alterações fisiológicas ocorrentes durante o amadurecimento de melão, sob duas condições de armazenamento.

\section{MATERIAL E MÉTODOS}

Melão tipo Orange, cv. Orange Flesh, provenientes da região de Mossoró - RN, logo após colhidos, foram lavados com água e sabão e selecionados segundo uniformidade de maturação. O lote dos frutos foi subdividido em dois, sendo um lote tratado, no mesmo dia da colheita, com 1-MCP na dosagem de 300 nL.L ${ }^{-1}$, de acordo com Terao (26) em câmaras fechadas por 12 horas em temperatura ambiente (29 $\pm 1^{\circ} \mathrm{C}$ e umidade relativa de $65 \pm 2 \%$ ), e o outro foi utilizado como Testemunha, não tendo recebido tratamento.

Em seguida, todos os frutos foram inoculados com uma suspensão de conídios de F. pallidoroseum na concentração de $1 \times 10^{7}$ conídios.ml ${ }^{1}$ em quatro pontos eqüidistantes na superfície que fora, previamente ferida com um conjunto de seis agulhas, com diâmetro $2 \mathrm{~mm}$ cada, a uma profundidade de, aproximadamente, $3 \mathrm{~mm}$. Depois, esses frutos foram acondicionados em caixas de papelão, em número de quatro por caixa os quais foram incubados durante $36 \mathrm{~h}$ em câmara úmida. Depois de retirados da câmara úmida, esses frutos foram separados aleatoriamente, em dois lotes de 16 caixas cada, os quais corresponderam a dois tratamentos: T1 - com 1-MCP; T2 Testemunha (sem 1-MCP). Em seguida, os dois lotes foram armazenados sob duas condições: ambiente $\left(29^{\circ} \pm 1{ }^{\circ} \mathrm{C}\right.$ e umidade relativa de $65 \pm 2 \%)$ e, sob refrigeração $\left(10 \pm 2{ }^{\circ} \mathrm{C}\right.$ e umidade relativa $90 \pm 3 \%$ ) por 15 dias. Após esse período, os frutos armazenados em câmara frigorífica foram transferidos para condições ambiente por mais nove dias, de modo a simular o período de permanência em porões refrigerados quando do transporte marítimo do Brasil à Europa, mais o período de prateleira após a distribuição.

$\mathrm{O}$ ensaio foi conduzido em delineamento inteiramente casualizado em arranjo fatorial $2 \times 2$ (tratamentos com 1-MCP x ambiente de armazenamento), com quatro repetições, sendo a unidade experimental constituída por um fruto. Foram avaliadas as seguintes variáveis: atividade respiratória $\left(\mathrm{mg} \mathrm{CO}_{2} \cdot \mathrm{Kg}^{-1} \cdot \mathrm{h}^{-1}\right)$ e produção de etileno $\left(\mathrm{ul}_{2} \mathrm{C}_{2} \mathrm{H}_{4}\right.$ $\left.\mathrm{Kg}^{-1} \cdot \mathrm{h}^{-1}\right)$ utilizando-se cromatógrafo à gás CG modelo DANI 86.10 com o auxílio de detector de condutividade térmica $\left(150{ }^{\circ} \mathrm{C}\right)$ para $\mathrm{CO}_{2}$ e ionização de chama $\left(200^{\circ} \mathrm{C}\right)$ para $\mathrm{C}_{2} \mathrm{H}_{4}$, em coluna PORAPAK - N (4 m x 3,2 mm). Uma amostra de $5 \mathrm{ml}$ da atmosfera produzida pelo fruto sadio e íntegro em recipiente fechado era coletada e analisada diariamente, comparando-se com amostra padrão de $\mathrm{CO}_{2}$ e outra amostra de $5 \mathrm{ml}$ comparando-se com amostra padrão de $\mathrm{C}_{2} \mathrm{H}_{4}$ Perda de massa fresca (\%), através de pesagem diária dos frutos e a cor da casca e polpa com o auxílio de colorímetro MINOLTA modelo CR300. Para esta avaliação, efetuaram-se duas leituras em pontos eqüidistantes na superfície e na polpa da fruta, considerando-se três variáveis que definem a cor: luminosidade (L), cromaticidade (Croma) e ângulo Hue. A firmeza da polpa $(\mathrm{N})$ foi avaliada por meio de penetrômetro modelo FT 327 ( 3 a 27lb), considerando-se a média de quatro medições em pontos opostos na polpa de frutos cortados longitudinalmente. $\mathrm{O} \mathrm{pH}$ da polpa foi determinado utilizando-se um potenciômetro digital com eletrodo de membrana de vidro e a Acidez total titulável (ATT) com auxílio de um titulador automático METTLER DL 12. Os sólidos solúveis totais ( ${ }^{0}$ Brix) pela leitura em refratômetro digital ATAGO PR 101 de acordo com Kramer (17) e os açúcares solúveis totais (AST) em espectrofotômetro a $620 \mathrm{~nm}$, sendo a extração feita com álcool $80 \%$ e determinado com o reagente antrona de acordo com a metodologia de Yemn \& Willis (30).

As avaliações de atividade respiratória, produção de etileno e perda de massa fresca, foram feitas utilizando-se os mesmos frutos, durante 
11 dias após a colheita, enquanto todos estavam intactos, sendo suspensas, a partir de então, em virtude do descarte de frutos deteriorados na Testemunha, armazenada em ambiente não refrigerado.

Exceto as avaliações de atividade respiratória e produção de etileno e perda de massa fresca, que foram efetuadas diariamente, as demais variáveis foram avaliadas em oito diferentes períodos: a cada três dias, quando armazenados em temperatura ambiente; e a cada cinco dias, quando sob refrigeração. Para avaliação de severidade da doença utilizou-se a seguinte escala de notas (26): $0=$ ausência de lesão; $1=$ soma de lesões até $10 \mathrm{~mm}$ de diâmetro; $2=$ soma de lesões de 11 a 20 $\mathrm{mm} ; 3=$ soma de lesões de 21 a $40 \mathrm{~mm}$; $4=$ soma de lesões de 41 a 60 $\mathrm{mm}$; e $5=$ soma de lesões maiores que $60 \mathrm{~mm}$.

$\mathrm{Na}$ avaliação da abscisão peduncular utilizou-se, também, uma escala de notas (26), considerando-se como nota $0=0 \%$ de abscisão do pedúnculo; $1=25 \%$ de abscisão do pedúnculo; $2=26-50 \%$ de abscisão do pedúnculo; $3=51-75 \%$ de abscisão do pedúnculo; $4=76-100 \%$ de abscisão do pedúnculo.

A análise de variância foi realizada pelo programa estatístico SAS (GLM Procedures, SAS Institute, Cary, NC) e as médias dos resultados comparadas pelo Teste de Tukey (Pd"0,05).

\section{RESULTADOS E DISCUSSÃO}

Houve efeito significativo do 1-MCP e da refrigeração, bem como da interação dessas duas variáveis no retardamento da maturação dos frutos de melão tipo Orange cv. Orange Flesh.

Dentre as variáveis avaliadas, a firmeza da polpa é considerada
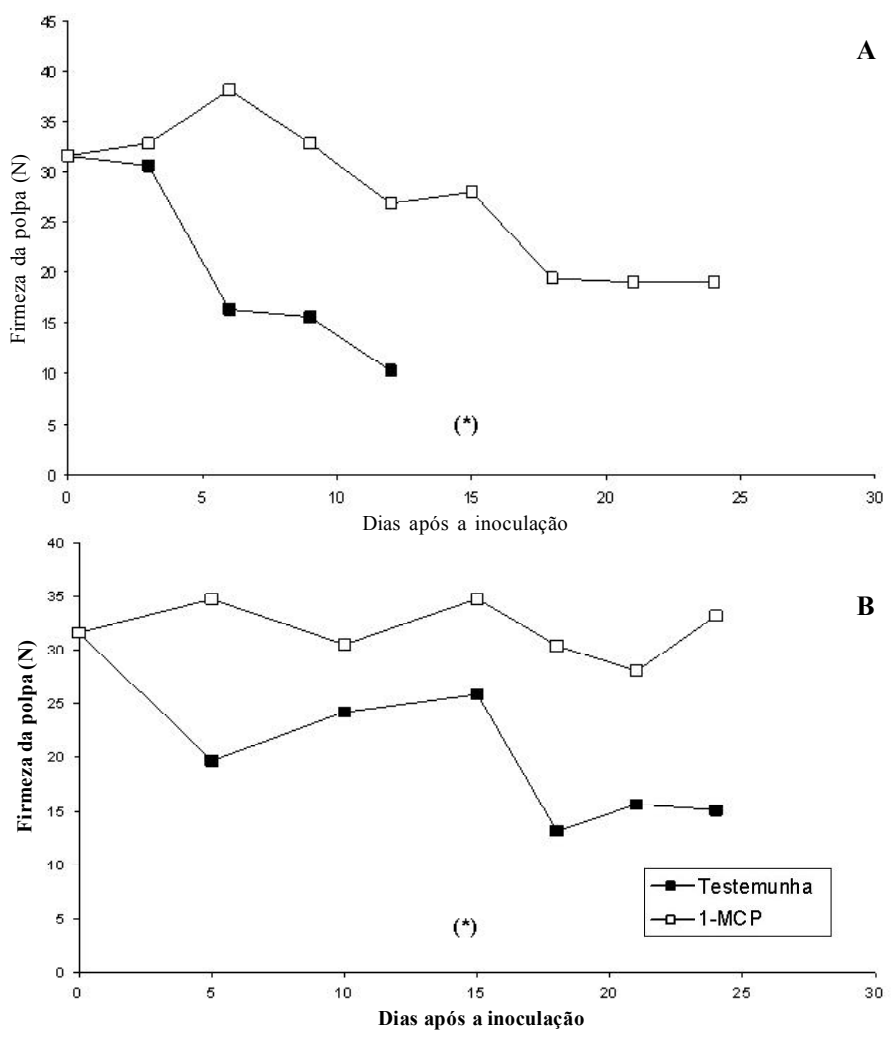

Figura. 1. Firmeza da polpa de melões Orange cv. Orange Flesh, tratados com 1-MCP (300 nL.L $\left.{ }^{-1}\right)$ e não tratados, inoculados com Fusarium pallidoroseum, armazenados sob (A) condição ambiente $\left(29^{\circ} \pm 1{ }^{\circ} \mathrm{C}\right.$ e umidade relativa de $65 \pm 2 \%)$ e (B) sob refrigeração $\left(10 \pm 2{ }^{\circ} \mathrm{C}\right.$ e umidade relativa $90 \pm 3 \%$ ). (*) Dia em que os frutos foram retirados da refrigeração. como uma das mais importantes características pós-colheita, uma vez que influencia tanto a palatabilidade, como os métodos de colheita, manuseio e transporte, a resistência a doenças e, conseqüentemente, a vida útil do fruto (21), sendo utilizada como índice de maturidade prático para alguns frutos (10).

Enquanto frutos da testemunha, armazenados à temperatura ambiente apresentaram queda drástica na firmeza, reduzindo de $30 \mathrm{~N}$ para, aproximadamente $15 \mathrm{~N}$ em apenas cinco dias, sendo descartados aos 12 dias da colheita, frutos tratados com 1-MCP mantiveram valores de firmeza praticamente inalterados até o $15^{\circ}$ dia após inoculação com o fitopatógeno, decrescendo gradativamente a partir desse período. Mesmo assim, foram verificados, até o $24^{\circ}$ dia, valores próximos a $20 \mathrm{~N}$ (Figura 1). Estes resultados estão em concordância com aqueles obtidos por Almeida et al.(3) para melão do tipo Cantaloupe.

Frutos da Testemunha armazenados sob refrigeração, conservaram médias de firmeza próximos a $25 \mathrm{~N}$, decrescendo rapidamente a partir do $15^{\circ}$ dia, quando colocados na temperatura ambiente. Porém, quando se combinou o 1-MCP à refrigeração observou-se efeito aditivo sobre o retardamento do amadurecimento, sendo que a firmeza de frutos manteve-se semelhante ao do dia da colheita, durante todo o período de avaliação, mesmo quando esses foram mantidos em ambiente não refrigerado durante 9 dias adicionais (Figura 1).

A manutenção na firmeza do fruto é um fator muito importante na resistência a podridões, uma vez que facilita o manuseio, diminui a ocorrência de ferimentos e conseqüentemente reduz o potencial de infecções.

Outro importante indicador de colheita utilizado, principalmente para algumas cultivares de melão do grupo Cantaloupe, é o grau de abscisão do pedúnculo, que deve ser mantido intacto, uma vez que, quando totalmente rachado, prejudica a vida pós-colheita de frutos, além de constituir uma porta de entrada para patógenos agentes causadores das podridões de pedúnculo (8). De maneira semelhante à firmeza da polpa, observou-se que o tratamento com 1-MCP, independente do armazenamento refrigerado retardou a abscisão do pedúnculo por 15 dias, em média (Figura 2).

Constatou-se uma íntima relação entre a evolução do amadurecimento e o desenvolvimento de podridão de frutos, concordando com a hipótese sustentada por Leverentz et al. (19) de que frutos com maturação mais lenta são mais resistentes à podridão. O tratamento com 1-MCP ao mesmo tempo em que retardou a maturação de frutos, controlou a podridão, atrasando o seu início, em média 12 dias em relação à Testemunha, que em armazenamento ambiente já apresentava, aos cinco dias após a colheita, valores elevados

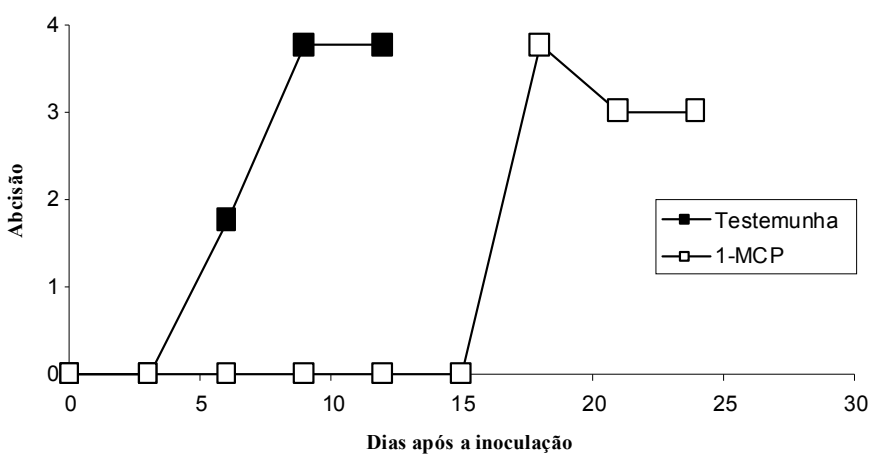

Figura. 2. Abscisão do pedúnculo de frutos de melão Orange, cv. Orange Flesh, utilizando-se Escala de Notas (0-4) inoculados com Fusarium pallidoroseum, tratados com 1-MCP (300 nL.L $\left.{ }^{-1}\right)$ e não tratados, armazenados sob condições sob condição ambiente $\left(29^{\circ} \pm 1{ }^{\circ} \mathrm{C}\right.$ e umidade relativa de $65 \pm 2 \%$ ). 

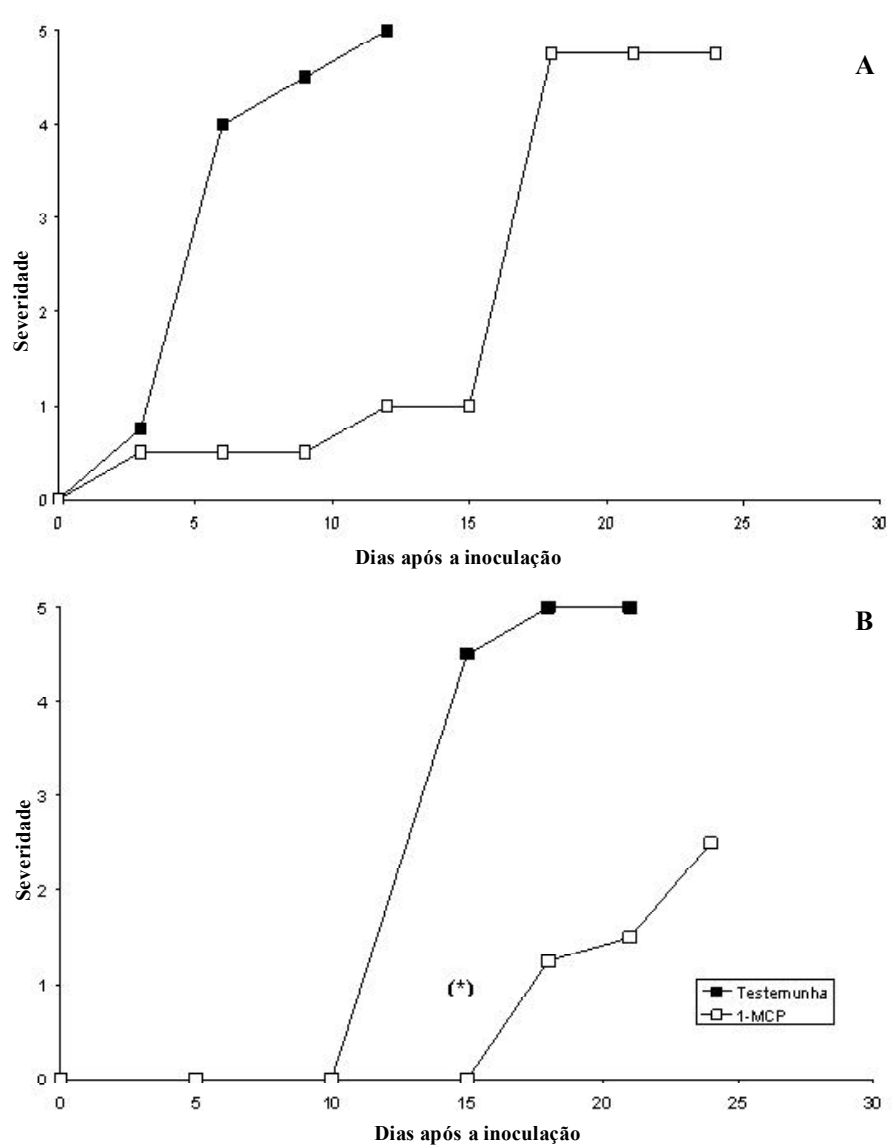

Figura 3. Severidade da podridão provocada por Fusarium pallidoroseum em melão Orange cv Orange Flesh pela Escala de Notas (0 a 5), tratados com 1-MCP (300 nL.L $\left.{ }^{-1}\right)$ e não tratados, armazenados sob (A) condição ambiente $\left(29^{\circ} \pm 1{ }^{\circ} \mathrm{C}\right.$ e umidade relativa de $\left.65 \pm 2 \%\right)$ e (B) refrigeração (10 $\pm 2{ }^{\circ} \mathrm{C}$ e umidade relativa $90 \pm 3 \%$ ). (*) Dia em que os frutos foram retirados da refrigeração.

de severidade. Em armazenamento refrigerado, a podridão iniciou a partir do $10^{\circ}$ dia para frutos da Testemunha, atingindo valor máximo de severidade aos 15 dias da colheita; ao passo que, frutos tratados com 1-MCP, iniciaram o desenvolvimento da podridão aos 15 dias depois de inoculados com o F. pallidoroseum, apresentando incremento lento da doença, mesmo quando retirados da refrigeração (Figura 3).

Resultados semelhantes foram obtidos por Terao et al. (24), em que melões do tipo Orange tratados com 1-MCP, mantiveram baixo nível de severidade de podridão causada por F. pallidoroseum, mesmo quando foram armazenados em temperatura ambiente, enquanto frutos da testemunha apresentaram elevados níveis de severidade desde a primeira avaliação, aos 5 dias a colheita, evoluindo rapidamente para o descarte. Enquanto Terao et al. (25) observaram que houve interação altamente significativa, no controle da podridão de frutos de meloeiro, entre o tratamento com 1-MCP, período e ambiente de armazenamento.

Segundo Prusky \& Lichter (20), patógenos causadores de doenças em pós-colheita, penetram por ferimentos, por aberturas naturais ou diretamente pela cutícula intacta, e podem permanecer quiescentes, como microorganismos biotróficos, durante o desenvolvimento da fruta, transformando-se em necrotróficos, causadores de podridões, durante o amadurecimento e senescência. Isso ocorre em função de modificações bioquímicas, como a perda de mecanismos naturais que protegem as frutas imaturas contra o ataque de fungos como: a composição nutricional impróprio ao desenvolvimento do patógeno, a presença de compostos antifúngicos pré-formados ou induzidos, o ambiente inadequado para ativação de fatores de patogenicidade.

O tratamento com 1-MCP contribuiu significativamente na redução da respiração enquanto frutos testemunha mantiveram elevados níveis de respiração até o final das avaliações. Os frutos testemunha, a partir do $7^{\circ}$ dia, iniciaram uma nova elevação na emissão de $\mathrm{CO}_{2}$ em condições ambientais normais, provavelmente pela colonização intensa do $F$. pallidoroseum (Figura 4). Também, a refrigeração contribuiu para reduzir a respiração, sendo a combinação das duas variáveis, 1-MCP e refrigeração, aditivas com os menores valores de emissão de $\mathrm{CO}_{2}$ durante todo o período de avaliação. Os menores valores de emissão de $\mathrm{CO}_{2}$ no pico de respiração ocorreram em frutos de melão tratados com 1-MCP, independente das condições de armazenamento.

Com relação à emissão de etileno, frutos testemunha apresentaram pico ao redor do $5^{\circ}$ dia após a colheita com valor ao redor de $20 \mu \mathrm{l}$ $\mathrm{C}_{2} \mathrm{H}_{4} \cdot \mathrm{Kg}^{-1} \cdot \mathrm{h}^{-1}$, declinando a partir de então, apresentando a partir do $10^{\circ}$ dia uma tendência à elevação, no mesmo padrão que ocorreu com relação à emissão de $\mathrm{CO}_{2}$. Provavelmente isso se deva ao etileno produzido pela colonização fúngica (Figura 4). Ilag \& Curtis (11) estudaram vários grupos de fungos e relataram que 58 das 228 espécies examinadas produziram etileno. Diversos fungos fitopatogênicos usam a metionina como um precursor de etileno incluindo espécies de Verticillium, Fusarium e Colletotrichum (27).

Em frutos tratados com 1-MCP com ou sem refrigeração e Testemunha sob refrigeração não se detectou emissão de etileno durante o período de avaliação, demonstrando que tanto o tratamento com 1MCP como a refrigeração atua de maneira efetiva no retardamento da produção de etileno (Figura 4).

Almeida et al. (3) observaram que o tratamento com 1-MCP diminuiu a intensidade, bem como atrasou os picos de produção de etileno em melão Cantaloupe. Segundo Suslow et al. (23), a sensibilidade destes frutos ao etileno exógeno é alta, logo a exposição a esse gás ou mesmo o contato com frutos, que apresentem alta taxa de liberação durante o armazenamento ou transporte, pode acelerar a senescência.


Figura 4. (A) Produção de $\mathrm{CO}_{2}$ e (B) etileno por frutos de melão Orange cv. Orange Flesh, inoculados com Fusarium pallidoroseum, tratados com 1-MCP (300 nL. $\left.\mathrm{L}^{-1}\right)$ e não tratados, armazenados sob condição ambiente $\left(29^{\circ} \pm 1{ }^{\circ} \mathrm{C}\right.$ e umidade relativa de $\left.65 \pm 2 \%\right)$ e refrigeração $\left(10 \pm 2{ }^{\circ} \mathrm{C}\right.$ e umidade relativa $90 \pm 3 \%$ ). 


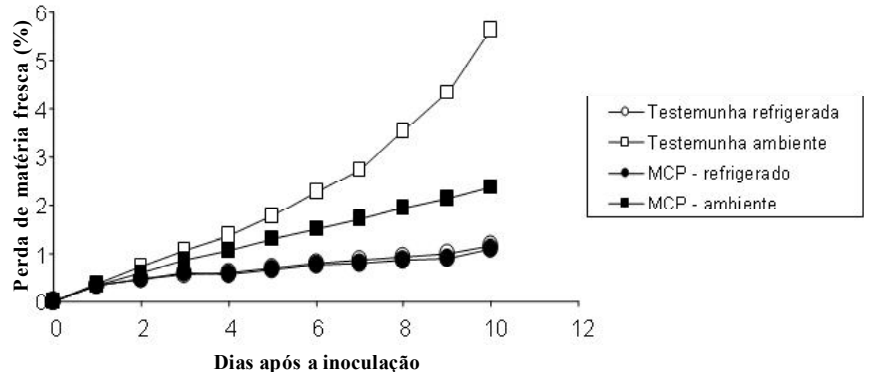

Figura 5. Perda de massa por frutos de melão Orange cv. Orange Flesh tratados com 1-MCP (300 nL. $\left.\mathrm{L}^{-1}\right)$ e não tratados, inoculados com Fusarium pallidoroseum, armazenados sob condição ambiente $\left(29^{\circ} \pm 1{ }^{\circ} \mathrm{C}\right.$ e umidade relativa de $65 \pm 2 \%)$ e refrigeração $\left(10 \pm 2{ }^{\circ} \mathrm{C}\right.$ e umidade relativa $90 \pm 3$ $\%)$.

Em relação à perda de massa, ocorreu influência significativa nos frutos de melão tratados com 1-MCP, os quais perderam peso em torno de $2,34 \%$, enquanto que os frutos Testemunha perderam ao redor de 5,49\%, durante o período de avaliação, quando armazenados à temperatura ambiente. Quando armazenados sob ambiente refrigerado, esta perda caiu para $1,09 \%$ em ambos os tratamentos (Figura 5).

Kader (16) atribuiu à perda de massa a causa principal da deterioração no armazenamento, resultando em perdas quantitativas e qualitativas. Esta perda de massa é atribuída à perda de umidade e ao consumo de açúcares durante a respiração (5). Este consumo de açúcares pode ser constatado através da queda no teor de sólidos solúveis totais ( ${ }^{\circ}$ Brix) e açúcares solúveis totais observados durante o período de armazenamento, sendo mais pronunciado para frutos testemunha (Dados não apresentados).

Com relação a variáveis que definem a cor (luminosidade, cromaticidade e ângulo Hue) observou-se, tanto para cor da casca como da polpa, pequenas variações durante o período de avaliação, demonstrando que o 1-MCP não influiu significativamente nessas variáveis (Dados não apresentados).

Da mesma maneira, em relação ao $\mathrm{pH}$ e acidez total titulável, não se observaram alterações significativas durante o período de avaliação entre os tratamentos com e sem 1-MCP, e entre as diferentes condições de armazenamento. Verificou-se valores médios de 6,4 para pH e 0,09 \% para acidez total titulável, estando os resultados em concordância com os obtidos por Almeida et al. (3) em melão Cantaloupe. Concluindo-se que o 1-MCP não alterou significativamente as características organolépticas dos frutos tratados.

Concluiu-se, então, neste trabalho que o 1-MCP retarda a maturação de melão cv. Orange Flesh, auxiliando significativamente no controle de podridão causada por $\boldsymbol{F}$. pallidoroseum, apresentando efeito sinérgico quando associado ao armazenamento refrigerado.

Frutos de meloeiro Orange cv. Orange Flesh tratados com 1-MCP apresentaram pequenas variações de cor de casca e polpa, mantiveram a firmeza da polpa, redução na atividade respiratória e produção de etileno, bem como em variáveis ligadas à maturação, como a abscisão do pedúnculo, não influenciando significativamente nos ligados à qualidade dos frutos, como o teor de sólidos solúveis totais, açúcares solúveis totais, $\mathrm{pH}$ e acidez total titulável.

\section{REFERÊNCIAS BIBLIOGRÁFICAS}

1. Abdi, N.; Mcglasson, W.B.; Holford, P.; Willians, M. \& Mizrahi, Y. Responses of climateric and supressed climateric plums to tre- atment with propylene and 1-methylcyclopropene. Postharvest Biology and Technology, Amsterdam, v.14, p.29-39. 1998.

2. Almeida, J.G. de F. Barreiras às exportações de frutas tropicais. Fitopatologia Brasileira, Brasília, v. 27, p.7-10. 2002.

3. Almeida, A.S.; Alves, R.E.; Filgueiras, H.A.C.; Menezes, J.B.; Pereira, M.E.C.; Abreu, C.R.A. de. Conservação de melão Cantaloupe "acclaim" submetido à aplicação pós-colheita de 1-MCP. Horticultura Brasileira, Brasília, v.19 (supl.): CD-ROM. 2001.

4. Benato, A.E.; Cia, P.; Souza, N.L. Manejo de doenças de frutas pós-colheita. Revisão Anual de Patologia de Plantas, Passo Fundo, v.9, p.403-440. 2001.

5. Chitarra, M.I.F; Chitarra, A.B. Pós-colheita de frutos e hortaliças: fisiologia e manuseio. Lavras. UFLA, 2005. 785 p.

6. Dias, R.C.S.; Terao, D. Doenças das cucurbitáceas. In: Oliveira, S.M.A.O.; Terao, D.; Dantas, S.A.; Tavares, S.C.C.H. (Ed.). Patologia pós-colheita Frutas, olerícolas e ornamentais tropicais. Brasília. Embrapa Informação Tecnológica. p. 595-627. 2006.

7. Fan, X.; Blankenship, S.M.; Matheis, J.P. 1-Methylcyclopropene inhibits apple ripening. Journal of the American Society for Horticultural Science, Alexandria, v.124, p.690-695. 1999.

8. Filgueiras, H.A.C.; Menezes, J.B.; Alves, R.E.; Costa, F.V.; Pereira, L.S.E.; Gomes Junior, J. Colheita e manuseio pós-colheita. In: Alves, R.E. (Org.). Melão pós-colheita. Brasília. Embrapa-SPI, p. 23-41, 2000

9. Harris, D.R.; Seberry, J.A.; Wills, R.B.H.; Spohr, L.J. Effect of fruit maturity on efficiency of-methylcyclopropene to delay the ripening of bananas. Postharvest Biology and Technology, Amsterdam, v.20, p.303-308. 2000.

10. Huber, D.J. The role of cell wall hidrolases in fruit softening. Horticultural Reviews, Westport, v.5, p.169-219. 1983.

11. Ilag, L.; Curtis, R.W. Production of ethylene by fungi. Science, Washington, v.159, p.1357-1358. 1968.

12. Jeffreis, P.; Dodd, J.C.; Jeger, M.J.; Pumbley, R.A. The biology and control for Colletotrichum species on tropical fruit crops. Plant Pathology, London, v.39, p.343-366. 1990.

13. Jiang, Y.; Joyce, D.C.; Macnish, A. Extension of the self life of banana fruit by 1-methylcyclopropene in combination with polyethylene bags. Postharvest Biology and Technology, Amsterdam, v.16, p.187-193. 1999a.

14. Jiang, Y.; Joyce, D.C.; Macnish, A. Responses of banana fruit treatment with 1-methylcyclopropene. Journal of Plant Growth Regulation, Dordrecht, v.28, p.77-82. 1999 b.

15. Kande, H. Ethylene biosynthesis. Annual Review of Plant Physiology and Plant Molecular Biology, Palo Alto, v. 44, p.283-307. 1993 .

16. Kader, A.A. Postharvest biology and technology: an overview. In: Kader, A.A. (Ed.). Postharvest technology of horticultural crops. California: University of California. 1992. p. 15-20.

17. Kramer, A. Fruits and vegetables. In: Kramer, A.; Twig, B. Quality Control for Food Industry. Connecticut: AVI, v.2, p.157 $227,1973$.

18. Ku, V.V.V.; Wills, R.B.H. Effect 1-methylcyclopene on the storage life of broccoli. Postharvest Biology and Technology, Amsterdam, v.17, p.127-132. 1999.

19. Leverentez, B.; Conway, W.S.; Janisiewicz, W.J.; Safner, R.A.; Camp, M, J. Effect of combining MCP treatment, heat treatment and biocontrol on the reduction of postharvest decay of 'Golden Delicious' apples. Postharvest Biology and Tecnology, Amsterdam, v.27, p.221 - 233. 2003.

20. Prusky, Dov.; Lichter, A. Mechanisms modulating fungal attack in post-harvest pathogen interations and their control. European Journal of Plant Pahtology, Netherlands, v. 121, p.281289. 2008.

21. Seymour, G.B.; Gross, K.C. Cell wall disassembly and fruit softening. Postharvest Biology and Technology, Amsterdam, v.7, p.45-52. 1996.

22. Sisler, E.C.; Serek, M. Inhibitors of ethylene responses in plants at the receptor level: recent developments. Physiologia Plantarum, Copenhagem, v.100, p.577-582. 1997.

23. Suslow, T.V.; Cantwell, M.; Michell, J. Honey dew melon - re- 
commendations for maintaining postharvest quality. Disponível em: $<$ http://postharvest.ucdavis.edu/ProduceFacts/Fruit/ honeydew.html $>$ Acesso em: 10 set. 2003.

24. Terao, D.; Oliveira, S.M.A.; Viana, F.M.P.; Alves, R.E.; Rossetti, A.G.; Moura, R.D. Avaliação de 1-metilciclopropeno (1-MCP) no controle de doenças pós-colheita em frutos em meloeiro. Summa Phytopathologica, Botucatu, v.31, n.3, p. 232-235. 2005.

25. Terao, D.; Oliveira, S.M.A.; Viana, F.M.P.; Alves, R.E.; Rossetti, A.G.; Gondim, D.M.F. Efeito de 1-metilciclopropeno (1-MCP) combinado à refrigeração no controle de podridão pós-colheita em frutos de melão. Proceedings of the Interamerican Society for Tropical Horticulture, Fortaleza, v.47, p.53-57. 2003.

26. Terao, D. Estratégias de controle de podridões em pós-colheita de frutos de meloeiro. 2003. 144p. Tese (Doutorado em Fitopatologia), Universidade Federal Rural de Pernambuco,
Recife, Pernambuco.

27. Tzeng, D.D.; De Vay, J.E. Ethylene production and toxicity of methionine and its derivatives with riboflavin in cultures of Verticillium, Fusarium and Colletotrichum species to light. Physiologia Plantarum, Copenhagem, v.62, p. 545-552. 1984.

28. Ventura, J.A. Manejo de doenças e produção integrada de frutas tropicais. Fitopatologia Brasileira, Brasília, v.28 (supl.), p.5761. 2003.

29. Vilas Boas, E.V.B. 1-MCP: um inibidor da ação do etileno. In: Pozza, E.A.; Oliveira, F.A. Anais, Simpósio de Controle de Doenças de Plantas: Patologia Pós-colheita de Frutos e Hortaliças, Lavras, p. 24-30. 2002

30. Yemn, E. W.; Willis, A.J. The estimation of carbohydrate in plant extracts by anthrone. The Biochemical Journal, London, v. 57 , p. $505-514.1954$ 